Discussion Papers in Economics and Econometrics

\begin{tabular}{|l||}
\hline Fast Bargaining in Bankruptcy \\
David Benjamin \\
No. 0601 \\
\hline
\end{tabular}

This paper is available on our website http://www.socsci.soton.ac.uk/economics/Research/Discussion_Papers 


\title{
Fast Bargaining in Bankruptcy
}

\author{
David Benjamin * \\ University of Southampton \\ Original Version, December 31, 2003 \\ This Version, October 2004
}

*I am grateful to V.V. Chari for his continued support and guidance. I also thank Larry Jones, Michele Boldrin, Andrew McLennan and Jan Werner for their suggestions. I have also benefited greatly from conversations with Alexander Ueberfeldt, Sami Alpanda, Felipe Meza, Sanghoon Lee, Adrian Peralta-Alva, Suqin Ge, and Oksana Leukhina. I also thank seminar participants at Southampton University, Tel Aviv University, University of Haifa, Ben Gurion, University of Minnesota, Federal Reserve Bank of Minneapolis, The Society for Economic Dynamics Meetings and the Summer Econometric Society Meetings for comments. The remaining errors are mine. The views expressed in here are those of the author only. 


\begin{abstract}
I combine two previously separate strands of the bargaining literature to present a bargaining model with both one-sided private information and a majority vote for proposals to go into effect. I use this model to show that the US bankruptcy code produces shorter delays and higher welfare than the UK law.

I consider the bargaining that occurs in bankruptcy between an informed firm and a set of uninformed creditors over a set of claims against the firm. The agents have an infinite horizon to bargain and cannot commit to a schedule of future offers. If individual creditors can be treated differently and a majority vote is required for the acceptance of new claims, adding creditors increases the probability of reaching agreement by the end of any given period. The US regime has these features. I give numerical examples which show the efficiency gains from increasing the number of creditors are significant.

The UK voting rule allows one creditor a veto of all plans. Replacing the majority voting rule with the UK voting rule and allowing only the creditor with the veto to suggest plans, I show that the UK regime has longer delays and is less efficient than the US regime as long as the US regime has multiple creditors.
\end{abstract}

\title{
1 Introduction
}

In this paper, I consider the process of debt renegotiation between a firm and its creditors in bankruptcy. The management and the creditors bargain over new claims that the firm pays. The current management has private information on its ability to run the firm, which affects bargaining. I show that the nature of the bankruptcy law can have large effects on the size of the inefficiencies in bargaining.

I compare bargaining outcomes with two different bankruptcy laws. Under the first law, a firm can leave bankruptcy if a set of new claims, or a plan, passes a majority vote among the creditors and is approved by the firm. I label this law the "majority vote" law. Under the second law, one specific creditor is deemed to have a special priority which gives him the right to propose new contracts to the firm. The firm must in turn approve the plan. No other creditor needs to approve the plan. I refer to this law as the "controlling creditor" law.

There are two main results. The first is a comparison of delays in bankruptcy for the two systems. With just one creditor these two laws are identical in every detail and produce the same delays. With multiple creditors, however, the delays in bankruptcy are shorter under the majority vote law. With such a law, as more creditors are added the bargaining becomes faster. The majority vote law introduces a benefit from joining the "winning coalition." More creditors increases the relative benefit which leads creditors to offer the firm a higher probability of settlement.

The second main result is a welfare comparison. For such a comparison, I allow the firm to negotiate its initial contracts. The firm does not know its ability to run the firm until after it makes the investment. After it makes the investment, the firm's management learns its man- 
agerial ability and receives its profits. If the firm can afford the payments it has negotiated, it makes them to the creditors. Otherwise the firm enters bankruptcy. There are the same The majority vote law maximizes ex-ante welfare in this environment. There is a hold up problem here. The tough bargaining positions of the controlling creditor lead to more delays than greater revenues.

Speed in a bankruptcy law can be beneficial to the welfare derived from the institution of bankruptcy. A fast bankruptcy law makes debt finance more attractive. Potential managers and lenders can be unwilling to sign debt contracts if they believe that poor outcomes lead the firm to languish in the limbo of the bankruptcy court. A long stay in bankruptcy can bind key assets of the firm in unproductive uses and make long term relationships with clients and suppliers hard to establish and maintain. Similarly, potential lenders may be scared off by long bankruptcies. A prolonged bankruptcy can bind the lenders' collateral, create liquidity shortages, and generally introduce uncertainty. In practice, slow reorganization laws can lead the participants to liquidate otherwise viable firms.

I would also like to highlight a normative aspect of this result. One controversy in the study of bankruptcy is the degree in which the US bankruptcy law allows "winning coalitions" to form. This paper implicitly makes a normative argument for encouraging such coalitions.

The body of this paper is as follows. In the next section, I discuss the legal counterparts of these two laws, the US and UK bankruptcy laws. In Section 3, I discuss the related literature. In Section 4, I define the ex-post game focusing on the model with the majority vote law. I describe the equilibrium and present an existence and uniqueness result. In Section 5, I give the delay comparison. In Section 6, I perform the welfare comparison. Section 7 concludes.

\section{Description of US and UK Bankruptcy Laws}

I study the majority vote and controlling creditor laws because they capture distinguishing features of the US and the UK bankruptcy laws. ${ }^{1}$ A majority (or, to be precise, a weighted supermajority less than unanimity) vote among the creditors plays a key role in the passage of plans under the US law, or Chapter 11. In addition, the inferior treatment of a particular group of creditors is not sufficient to prevent a plan from going into effect.

To defend these claims, it is useful to describe the typical negotiations under Chapter $11^{2}$. Consider a firm whose debt is held entirely by unsecured creditors. First the firm negotiates the plan with a subset of the creditors who approve it by a majority vote. Once the Creditors' Committee and the court approve the plan, the firm puts the plan to a vote among the entire set of creditors through a fairly elaborate rule (Either a majority within every class or through cramdown). In general, an affirmative vote from the creditors that is less than unanimous is

\footnotetext{
${ }^{1}$ In the Legal Appendix, I give a more detailed description of the laws. I also document the details that are presented here. This is available on request and on the authors website.

${ }^{2}$ Alternatively, one can read ? for a full discussion on allowable discrimination in bankruptcy
} 
required.

Next, suppose an arbitrary unsecured creditor is treated less favorably than his counterparts in a plan that has passed the above votes. To keep the plan from going into effect, the inferiorly treated creditor must contest the plan at a "cramdown" hearing. In a cramdown hearing, the creditor may be able block the plan by convincing the judge that he has been treated in an inferior manner to creditors he shares priority with. However, there are many reasons the creditor may not do this. First the court can rule that there is a principled basis for the unequal treatment. ${ }^{3}$ Plus the discrimination may be hard for a judge to determine, especially if it takes the form of an unobservable payment. If no creditor draws out a cramdown hearing, the judge makes a determination whether the plan is in the firm's and the creditors' best interests and if so accepts the plan.

The controlling creditor law captures a unique feature of the UK law, or Receivership. In the UK, a necessary requirement for a firm to exit bankruptcy is that one specific, predetermined creditor supports the plan. This creditor has the powers the controlling creditor has in the model.

Since the model maps into the US and UK laws, comparing the potential inefficiencies in the data for these countries is informative. There are significant differences in the data. The delays in the reorganization of financial distressed firms in the US are typically much shorter. The mean of (UK) firms that successfully reorganize in receivership is 52 months as opposed to 21 months for firm in Chapter 11 (US). ${ }^{4}$

\section{Related Literature}

Other authors have attempted to categorize the effect of different sized sets of debtholders on outcomes of renegotiations. Such papers include, Gertner and Scharfstein (1991) and Bolton and Scharfstein (1996) where they tend to find multiple creditors makes debt more difficult to renegotiate. However they do not consider an environment where binding offers can be made to the entire set of creditors. Doing so changes the results and is important to the study of bankruptcy.

Nor is this the first paper that use a bargaining framework to model bankruptcy. Such papers include Hart and Moore (1994), Eraslan (2002), and Bebchuk and Chang (1992). They usually assume complete information and study different extensive forms than the one here.

The theoretical analysis builds on two canonical bargaining models. In order to talk to delays in bargaining between an informed firm and multiple uninformed creditors, I combine the Gul, Sonnenschein, and Wilson (1986) and Fudenburg, Levine, and Tirole (1985) model

\footnotetext{
${ }^{3} \mathrm{~A}$ frequent rationale for such a determination is that the extra-favorable treatment for another creditor occurs because such treatment is a "business necessity," or that a good relationship with the favored creditor is important for the continuation of the firm. A second rationale is that the discrimination is not significant enough to stop an otherwise acceptable plan.

${ }^{4}$ The data is presented and discussed in the Appendix. Measurement issues are discussed there.
} 
of bargaining among two agents with one-sided incomplete information with the Baron and Ferejohn (1989) model of bargaining where identically informed agents must approve plans through a majority vote.

\section{The Ex-Post Game}

I consider a firm entering bankruptcy with outstanding debts to a set of $n$ identical creditors. If $n>1$, I describe only bargaining with the US regime. For firms bargaining with the UK regime, I assume $n=1$. (Other agents do not participate.)

There exists one firm with type $\theta \in\left[\theta_{l}, \theta_{h}\right]$. The firm's type, $\theta$, is the present discounted value for the firm with its current management. It is only achievable for a firm outside bankruptcy and is private information to the firm, which is perfectly informed. The return to the firm if it is run by an outsider is $\theta_{l}$. Thus $\theta-\theta_{l}$ is the return to the firm's management ability. Firms inside bankruptcy have no returns. This captures both the negative effects financial distress and judicial oversight has with the management's ability to run the firm as it sees best. The creditors share an initial belief that $\theta$ has density $f$ and distribution $F$. The upper bound on the distribution of $\theta$ is $\theta_{h}$. The density is sufficiently smooth.

There are an odd number of uninformed creditors, $n$, with identical claims. All agents are risk neutral and have a common discount factor $\delta$.

At the beginning of period 1 , one creditor is chosen at random to propose a plan consisting of a set of payments to the $n$ creditors. This creditor is called the proposer.

All other creditors are called voters. After a plan is made the creditors and then the firm vote on the plan. If the firm and a majority of the creditors ( $\frac{n-1}{2}$ of the voters) accept the plan, it goes into effect immediately. If not the game goes on to the next period, where it repeats. The game concludes when a plan is passed.

Proposers' strategies are a map from the relevant history to the plans or $n$ payments;

$$
p_{i t} \text { (to himself) and }\left\{p_{j t}\right\}_{j \neq i} \text { (to other creditors) }{ }^{5}
$$

The remaining creditors, or "voters" simply vote. The firm's strategy is an acceptance/rejection decision.

The payoff to the firm is the discounted value of the firm's profits minus any payments the firm make, $\delta^{t}\left(\theta-\sum p_{k}\right)$

For the creditors, there are two payoffs to track, a proposer's payoff, $V$ and a voter's payoff, $W$. where the argument captures the upper bound on the agents' common belief.

The equilibrium concept is Weak Perfect Bayesian Equilibrium. ${ }^{6}$ Beliefs are shared. They

\footnotetext{
${ }^{5}$ Currently there is no restriction on plans that the proposer can suggest. I have extended the results in this paper to a model in which the minimum payment is fixed relative to the aggregate payment. This generalization is in the Technical Appendix, which is available from the author on request.

${ }^{6} \mathrm{~A}$ well known result is that for this class of models Weak Perfect Bayesian and Sequential Equilibria are equivalent.
} 
update as is standard in bargaining games. In all equilibria, in each period, those with types above a given threshold accept the creditors' offer. All others reject. Hence, each successive belief is a truncation of previous beliefs to an interval containing $\theta_{l}$.

I contend that there is a natural equilibrium outcome to study ${ }^{7}$. The proposer offers the largest payment to himself. He offers a smaller payment to a subset of creditors which form a minimum coalition. All other creditors are offered a zero payment. ${ }^{8}$.

The equilibrium can be described through a functional equation, in which the creditors' payoffs depend on the belief $\theta_{b}$ entering a given period. Letting $\Theta$ equal the set of all types, then the functional equation is presented through the following proposition.

Proposition 1. Consider the following set of functions: $\Theta \rightarrow R$, a payment to the proposer $p_{1}$; payment to the included voters $p_{-1}$; a belief updating function, $g$; value functions, $V, W$; and an aggregate payment function, $C=p_{1}+\frac{n-1}{2} p_{-1}$;

The above functions are a Weak Perfect Bayesian Equilibrium outcome if they satisfy Program 1:

\section{Program 1}

\section{Proposer's Problem}

For each $\theta_{b}$, a proposer with an upper bound on beliefs of $\theta_{b}$ chooses $\theta_{a}, p_{i}$, and $p_{j}$ to satisfy

DP

$$
V\left(\theta_{b}\right)=\max _{p_{i}, p_{j}, \theta_{a}} p_{i}\left(\frac{F\left(\theta_{b}\right)-F\left(\theta_{a}\right)}{F\left(\theta_{b}\right)}\right)+\delta\left(\frac{1}{n} V\left(\theta_{a}\right)+\frac{n-1}{n} W\left(\theta_{a}\right)\right) \frac{F\left(\theta_{a}\right)}{F\left(\theta_{b}\right)}
$$

s.t.

$$
\theta_{a}-p_{i}-\frac{(n-1)}{2} p_{j} \geq \delta\left(\theta_{a}-C\left(\theta_{a}\right)\right)
$$

with equality if $\theta_{a}>0$

$$
\begin{aligned}
p_{j}\left(\frac{F\left(\theta_{b}\right)-F\left(\theta_{a}\right)}{F\left(\theta_{b}\right)}\right)+\delta\left(\frac{1}{n} V\left(\theta_{a}\right)+\frac{n-1}{n} W\left(\theta_{a}\right)\right) & \frac{F\left(\theta_{a}\right)}{F\left(\theta_{b}\right)} \\
& =\delta\left(\frac{1}{n} V\left(\theta_{b}\right)+\frac{n-1}{n} W\left(\theta_{b}\right)\right)
\end{aligned}
$$

\footnotetext{
${ }^{7}$ In the BF model, there are a large multiplicity of equilibria. It is possible to generalize the refinement there to produce a unique equilibrium for some parameter values, however there is a good deal of arbitrariness in such extensions.

${ }^{8}$ This is the minimum allowed payment.
} 


$$
\theta_{l} \leq \theta_{a} \leq \theta_{b}
$$

II. And given $p_{i}, p_{j}, \theta_{a}$ and $V$ from DP the following relationships complete a fixed point argument:

$$
\begin{aligned}
& p_{1}\left(\theta_{b}\right)=p_{i} \\
& p_{-1}\left(\theta_{b}\right)=p_{j} \\
& C\left(\theta_{b}\right)=p_{1}\left(\theta_{b}\right)+\frac{n-1}{2} p_{-1}\left(\theta_{b}\right) \\
& W\left(\theta_{b}\right)=\frac{1}{2} p_{1}\left(\theta_{b}\right)\left(\frac{F\left(\theta_{b}\right)-F\left(g\left(\theta_{b}\right)\right)}{F\left(\theta_{b}\right)}\right) \\
&+\delta\left(\frac{1}{n} V\left(g\left(\theta_{b}\right)\right)+\frac{n-1}{n} W\left(g\left(\theta_{b}\right)\right)\right) \frac{F\left(g\left(\theta_{b}\right)\right)}{F\left(\theta_{b}\right)}
\end{aligned}
$$

The proof of this proposition is in the Appendix. Only a few of the above objects warrant a description.

(1) is the objective function of the proposer. In the next period, if he proposes again, he receives $V$. If not then he is offered the voter's payment, $W$.

(2) constrains the proposer such that his suggestion of lowest type to approve the plan is the lowest type that incentives dictate approve the plan. The incentive constraints of all other types of the firm do not bind.

(3) constrains the proposer to only suggest plans such that creditors for whom a ' $Y$ ' is needed for plans to pass vote as required.

(5) to (8) are primarily notational as they ensure that $V$ and $W$ correspond to actual equilibrium outcomes.

From here some manipulation is possible that highlights the role increasing creditors plays in terms of the impatience. Define a "quasi-discount factor as $\bar{\delta}(N)=\delta\left(\frac{1}{2}+\frac{1}{2 N}\right)$. Then the solution to our problem is the same as the solution to a standard problem given the proposer makes offers with a discount factor was de $\bar{l} t a$.

The main results rely on the quasi-discount factor decreasing in $n$. Hence, the results would be essentially the same if a supermajority short of unanimity is needed. ${ }^{9}$ With unanimity, the results are different. For unanimity, regardless of $n$, the quasi-discount factor equals the actual discount factor and changing the number of creditors does not affect outcomes.

\footnotetext{
${ }^{9}$ This is very important to the application where due to the complicated acceptance rule and judicial discretion, a better approximation of the US rule may be a supermajority rule greater than majority but short of unanimity.
} 


\subsection{Intermediate Results}

I generalize two results from the incomplete information bargaining literature in this section. Both pertain to equilibria that satisfy the Functional Equation. I show that if $\theta_{l}>0$, should an equilibria exist, the bargaining ends in a finite number of periods almost surely. I call this the Finite Ending Result. Using this result I present an existence and uniqueness theorem for equilibrium that satisfy the Functional Equation.

Proposition 2. Finite Ending Result If $\theta_{l}>0$, in any equilibrium that satisfies the Functional Equation, the bargaining lasts a finite number of periods.

The proof of the Finite Ending Result is a generalization of FLT. ${ }^{10}$ The result implies that if an equilibrium exists the bargaining must last a finite number of periods. Hence to show existence, I can consider only equilibrium candidates that must eventually produce agreement for sure. The equilibrium strategies must contain a plan that the lowest type $\theta_{l}$ accepts for sure. I can show such a plan exists and is part of an optimal strategy. From this plan I can construct the continuation payoffs for games in the second to last period of bargaining. Working inductively, I can prove both existence and uniqueness by calculating the unique equilibrium outcome in a given period when the expected continuation payoffs are derived from know equilibrium behavior. This result is useful, because it provides a characterization of equilibrium outcomes with small lower bounds on beliefs. When equilibrium outcomes have explicit characterizations, then the desired comparative static results are easy to show.

Theorem 1. Let $\theta_{l}>0$. There exists a unique equilibrium outcome which satisfies the (Simpler) Functional Equation generically up to a potential multiplicity of equilibrium outcomes in the initial period over a set of measure zero. ${ }^{11}$

The proof of this theorem is in the Appendix and again is a generalization of FLT and Ausubel and Deneckere (1989). A byproduct of the proof is a recursive description of the Equilibrium. There is the matter of existence if $\theta_{l}=0$. In this case I restrict the distribution to be of simple functional forms for all the results I derive. I prove existence by constructing the solution to the functional equation.

\section{Delay Comparisons}

In this section, I present the main result, the delay comparison which shows a primary difference between the two laws. The main result is that, as $n$ increases, the lowest type accepting the creditors' offer falls in every period and agreements are quicker. This result requires some

\footnotetext{
${ }^{10}$ Due to the length and lack of original contribution, it is available on request

${ }^{11}$ In period 1, the initial proposer may have more than one optimal choice of $P$ and $\theta_{a}$. But after this period, the equilibrium is entirely without mixed strategies. The generic restriction is that such a multiplicity of outcomes can occur at most on a countable subset of initial beliefs.
} 
qualification since even for the standard GSW and FLT models, the belief updating function, $g$, may not necessarily be monotone increasing in $\delta^{12}$ For this particular model, I am concerned about situations in which $g$ is increasing in $\bar{\delta}$ for a fixed $\delta$. In this event, I say that the "Impatience Effect" dominates, since in these situations a more impatient proposer engages in less screening of types. I prove the result for distributions on $\left[0, \theta_{h}\right]$ that are similar to the uniform distribution. I also provide an example to show the delay comparison holds for a standard gap case environment.

I prefer to state the theorem given the continuation rate The continuation rate is the probability the bargaining has not stopped given an initial upper bound on beliefs of $\theta_{b}, n$ creditors, and $t$ rounds of bargaining have occurred. That is:

$$
F_{t}^{n}\left(\theta_{b}\right)=\frac{F\left(\theta_{a t}^{n}\left(\theta_{b}\right)\right)}{F\left(\theta_{b}\right)}
$$

The term in the numerator $\theta_{a} t$ is simply the highest type to still bargain at the end of period $t$.

Theorem 2. [Delay Comparison] If $\theta_{l}=0$ and $\theta$ is uniformly distributed ${ }^{13}$

then $F_{t}^{n}\left(\theta_{h}\right)<F_{t}^{1}\left(\theta_{h}\right) \forall t$.

The proof of this proposition is in the appendix.

The quantitative effects of increasing the number of creditors with this highly fictionalized bankruptcy law can be seen through a numerical example. In Figure 5-5c, I normalize $\theta_{h}$ to 1 , and let $n=1$ and 9. The number of creditors is chosen to match US and UK observations. The first observation, $n=1$, is chosen to capture the equivalence between the UK law and the US law with one creditor. The second observation, $n=9$, is chosen to match the average number of classes of impaired debt for a firm in bankruptcy in the US as found by LoPucki and Whitford (1990).

I report the expected delays in number of periods associated with introducing more creditors in Figure $5 \mathrm{~b}$ as the discount factor varies or the cost of delay decreases. (One may think that calendar time affects bankruptcy renegotiations so that short time periods between offers are improbable.) As this figure shows, the expected delays in the one creditor model can be many multiples of the expected delays in the multiple creditor model which would be predictable because the quasi-discount factor diverges strongly from the actual discount factor for any $n$ as $\beta$ converges to one.

\subsection{Delay Comparison: Gap Case}

In the "Gap" case the forward looking nature of beliefs implies that the payment function $C$ is not differentiable. This is not a problem if there are two or few periods of bargaining. But for

\footnotetext{
${ }^{12}$ To the author's knowledge no necessary and sufficient condition exists for such a model.

${ }^{13}$ or polynomially distributed with the density $c x^{n}$
} 
most distributions, this can be a huge barrier to analytic results with as little as three periods of bargaining. I use examples to demonstrate a common but slightly weaker outcome, the expected length of bargaining decreases in $n$.

I highlight one example with a uniform distribution. To I pick $\theta_{l}=0.1, \theta_{h}=1.1, N=9$ and $\delta=0.97$ for the example I show. The output shown is the expected length of bargaining. As the graph shows, decreasing patience can have a strong effect. Among other distributions, the normal produces similar distributions.

However sufficient conditions for more general analytic theorems are difficult to show. In particular, global comparative statics on the belief updating function are rare. In the "Gap" case the forward looking nature of beliefs implies that the payment function $C$ is not differentiable and that the belief updating function, $g$ can have jumps if the belief is sufficiently high.

In the next section, I consider the game before the initial contracts are signed which, should the firm default, lead to the ex-post model of bankruptcy. For the ex-ante game, there are two important variables from the ex-post game: $X$ and $U$. To set notation, $X\left(\theta_{h}, n\right)$ and $U\left(\theta_{h}, n, \theta\right)$ are the expected payoffs to the entire set of creditors and type $\theta$ firm respectively, if the highest type in bankruptcy is $\theta_{h}$ and there are $n$ creditors who actively bargain with the firm in bankruptcy. I adopt the notational convention that $n$ refers to the number of creditors who actively participate in the ex post game, not the number of creditors who sign the initial contracts.

\section{Ex-Ante Contracts and Welfare}

I conclude the paper with an ex-ante welfare comparison for the two bankruptcy systems. I consider the problem for a firm which must sign a contract at $t=0$ in order to receive the necessary finance to earn $\theta$. I show that welfare is higher with the US system.

The model for this section is simple and is a natural extension of the previous model. Default in this model leads to the ex-post game described in Section 4. New to this model is a trade-off between avoiding delay costs should bankruptcy occur and obtaining sufficient funding for projects. I show that the US regime with $n$ creditors is ex-ante superior to the UK regime if solvent firms cannot enter bankruptcy. ${ }^{14}$ This is satisfied by the US bankruptcy code if judges can observe whether a firm's type is above a given threshold. I make the assumption because I do not want the payments negotiated by firms that settle in the first period of bankruptcy to determine the payments firms make outside bankruptcy.

This section is organized as follows. The ex-ante model is described first and welfare defined. Then, the welfare comparison is presented. (The Delay Comparison continues to hold trivially.)

\footnotetext{
${ }^{14}$ The qualitative result applies to a model in which managers must pay a sufficiently large fixed cost (in terms of their personal reputation for example) to enter bankruptcy. It does not apply to environments where entering bankruptcy is costless. In this case the qualitative results shift.
} 


\subsection{Ex-Ante Environment and Timing}

Consider a firm which can earn a stock return of $\theta$, where $\theta$ is restricted to be uniformly distributed on $[0,1]$. To achieve $\theta$, the firm must borrow $I$ to begin the project. At the time the firm seeks financing in period $0, \theta$ is unknown to the firm. To obtain financing, a firm signs a debt contract with an exogenous of the creditors. It has a value of $p$, which in the US, the creditors split evenly. In the UK, the payment to the receiver outside bankruptcy must differ from what the other creditors get. The debt contract gets the firm $I$. In the US, the burden of supplying the investment $I$ is split evenly among the creditors who sign the contract. This gives me identical creditors in bankruptcy. In the UK, the investment can be divided arbitrarily between the receiver and the other creditors. The investment market is perfectly competitive and all creditors have enough resources to meet whatever is demanded of them. The players are restricted to sign contracts such that all payments outside bankruptcy must be made in the first period.

The firm's ex-ante problem has the timing outlined in Figure 2. In period 0, the firm proposes the initial contract. This is a take-it-or-leave-it offer. The initial contract consists of the fraction of the required investment from each of the creditors in period zero and the payment the creditors are entitled to in period 1 . If all the creditors approve, the initial contract is signed and $I$ is delivered. In period 1, the firm learns its type. If the firm has sufficient resources, it makes the aggregate payment, $p$, and consumes $\theta-p$. If $\theta$ is beneath the promised aggregate payment, the firm enters bankruptcy. From here the timing is the same as in the ex-post model. The first offer occurs in the period the firm enters bankruptcy.

The distribution of the firm's type before any contracts are signed is called $G$. Once the contracts are signed and the types of the firm above the bankruptcy threshold make their payments, the distribution of firms inside bankruptcy, $F$, can be found from $F(\theta)=\frac{G(\theta)}{G\left(\theta_{h}\right)}$. Associated with $G$ is a density $g_{a}$. From here, I consider only welfare with $n$ creditors in both systems. I call welfare in country $C, Z_{C}$.

Welfare to the firm in the US in period 0 satisfies:

$$
Z_{U S}=\max _{\left\{\theta_{h}, p\right\}} \int_{0}^{\theta_{h}} U\left(\theta_{h}, n, \theta\right) g_{a}(\theta) d \theta+\int_{\theta_{h}}^{1}(\theta-p) g_{a}(\theta) d \theta
$$

such that

$$
\begin{aligned}
\theta_{h}-p & \geq 0 \\
X\left(\theta_{h}, n\right)+p\left(1-G\left(\theta_{h}\right)\right) & =I
\end{aligned}
$$

Constraint (10) is a wealth constraint which puts firms that cannot afford the prescribed payment into bankruptcy. Constraint (11) is a zero expected profit constraint on the entire set of creditors. 
Welfare in the UK system requires a different definition as the constraints change. For ease of exposition, let creditor one be the receiver. This is exogenous to the model. Creditor one receives $p_{1}$ outside bankruptcy. All other creditors receive $p_{-1}$ outside bankruptcy. Inside bankruptcy creditor one is the only creditor negotiating with the firm and the only one to receive positive payments. The other creditors receive zero payments. Likewise, $I_{1}$ and $I_{-1}$ refer to the expected investment from the receiver and from any other creditor, respectively. With this new notation, I can define welfare. Welfare in the UK to the firm in period 0 satisfies:

$$
Z_{U K}=\max _{\left\{\theta_{h}, p, p_{1}, p_{-1}, I_{1}, I_{-1}\right\}} \int_{0}^{\theta_{h}} U\left(\theta_{h}, 1, \theta\right) g_{a}(\theta) d \theta+\int_{\theta_{h}}^{1}(\theta-p) g_{a}(\theta) d \theta
$$

such that

$$
\begin{array}{r}
\theta_{h}-p \geq 0 \\
X\left(\theta_{h}, 1\right)+p_{1}\left(1-G\left(\theta_{h}\right)\right)=I_{1} \\
p_{-1}\left(1-G\left(\theta_{h}\right)\right)=I_{-1} \\
p_{1}+(n-1) p_{-1}=p \\
I_{1}+(n-1) I_{-1}=I
\end{array}
$$

There are two zero profit constraints: (14) for creditor one and (15) for the other creditors. Constraints (16) and (17) are identities that insure that the creditors as a whole receive the an aggregate payment equal to what the aggregate payment the firm makes and supply the aggregate investment the firm receives. The values of $p_{1}, p_{-1}, I_{1}$ and $I_{-1}$ that solve the problem are indeterminant. The receiver must supply a share of the investment equal to the bankruptcy payments, but anything else is kosher.

The welfare result is simple. If the investment can be afforded in the US, welfare is higher there.

\section{Proposition 3. Suppose}

I. $n>1$

II. $\delta$ is sufficiently high ${ }^{15}$

III. $I \leq \max _{\theta_{h}} X\left(\theta_{h}, n\right)+\theta_{h}\left(1-G\left(\theta_{h}\right)\right)$

then $Z_{U S}>Z_{U K}$.

The proof is in the Appendix.The result occurs because there is a hold up problem that reduces ex-ante welfare. For high discount factors, the patience of the firm implies that more

\footnotetext{
${ }^{15}$ Sufficiently high $=0.54$ if $n=9$.
} 
patient proposers generate more deadweight losses than revenues. Multiple creditors sacrifice these small revenues gains but avoid the larger deadweight losses. This eases the hold up problem.

For the above model, the Delay Comparison continues to hold. This is true simply because the continuation rate is constant in $\theta_{h}$ whenever $\theta$ has the uniform distribution.

\section{Conclusion}

From this study, advice can be found for governments choosing bankruptcy laws. On the simplest level, if the choice is a zero-one choice between the US and the UK bankruptcy laws, then they should choose the US law.

If the choice is for general principles to govern bankruptcy, the bankruptcy system should be designed, in part, to prevent inefficiencies ex-post. Picking a voting rule that facilitates agreements, such as a majority voting rule, can significantly reduce inefficiencies that are the result of lengthy delays. Conversely, requiring creditors to consent to any write down of their debt increases ex-post inefficiencies and as such is undesirable to a country choosing a bankruptcy law.

However, there is a caveat to the importance of a majority vote. A majority vote is only effective in limiting delays if individual creditors can be rewarded, relative to other creditors, for supporting plans that produce agreements. An equally key feature of bankruptcy design is that the division of claims between creditors must be open to negotiation. This is a much maligned feature of Chapter 11 but a key part of its success.

\section{References}

Altman, E., And A. Eberhart (1999): “The Equity Performance of Firms Emerging from Bankruptcy," Journal of Finance, 54(5), 1885-1869.

Ausubel, L. M., And R. Deneckere (1989): "Reputation in Bargaining and Durable Goods Monopoly," Econometrica, 57(3), 511-531.

Bailey, E., H. Groves, And C. Smith (2001): Corporate Insolvency Law and Practice. Butterworths, London, 2 edn.

Baron, D., And J. A. Ferejohn (1989): "Bargaining in Legislatures," American Political Science Review, 83(4), 1181-1206.

BebchuK, L. A., AND H. F. CHANG (1992): "Bargaining and the Division of Value in Corporate Reorganization,” Journal of Law, Economics and Organization, 8(2), 253-279. 
Benjamin, D. (2003): "Ex Ante Debt Contracts and Optimal Bankruptcy Proceedures,” .

Bolton, P., And D. S. Scharfstein (1996): "Optimal Debt Structure and the Number of Creditors," Journal of Political Economy, 104(1), 1-25.

Eklund, C. A., And L. W. Roberts (1997): "Bankruptcy Ethics: The Problem with Creditors' Committees in Chapter 11: How to Manage the Inherent Conflict Without Loss of Function," American Bankruptcy Institute Law Review, 5, 129-163.

ERASLAN, H. (2002): "Corporate Bankruptcy Reorganizations: Estimates from a Bargaining Model," Wharton School of Business.

Franks, J. R., AND K. G. Nyborg (1996): "Control Rights, Debt Structure and the Loss of Private Benefits: The Case of the UK Insolvency Code," Review of Financial Studies, 9(4), $1165-1210$.

FudenburG, D., D. LeVine, AND J. TIROle (1985): Infinite-horizon models of bargaining with one-sided incomplete informationchap. 5, pp. 73-98, Game-Theoretic Models of Bargaining. Cambridge University Press, Cambridge.

Gertner, R., AND D. Scharfstein (1991): "A Theory of Workouts and the Effects of Reorganization Law," Journal of Finance, 46(4), 1189-1222.

Gul, F., H. Sonnenschein, and R. Wilson (1986): "Fondations of Dynamic Monopoly and the Coase Conjecture," Journal of Economic Theory, 39(1), 155-90.

Hart, O., And J. Moore (1994): "A Theory of Debt Based on the Inalienability of Human Capital," Quarterly Journal of Economics, 109(4), 841-71.

LoPuCKI, L. M., And W. C. Whitford (1990): "Bargaining over Equity's Share in the Bankruptcy Reorganization of Large Publicly Held Companies," University of Pennsylvania Law Review, 139(125).

Meir, D. S., And T. Brown (1982): "Representing Creditors' Committees Under Chapter 11 of the Bankruptcy Code," American Bankruptcy Law Journal, 56, 217-231.

Merlo, A., AND C. WiLSON (1998): "Efficient delays in a stochastic model of bargaining," Economic Theory, 11(1), 39-95.

NORTH, D. C. (1991): “Institutions," Journal of Economic Perspectives, 5(1), 97-112.

PiCARDA, H. (2000): The Law Relating to Receivers, Managers and Administrators. Butterworths, London, 3 edn.

White, M. J. (1996a): The Costs of Corporate Bankruptcy: A U.S.-Europe Comparisonchap. 30, pp. 467-500, Corporate Bankruptcy Economic and Legal Perspectives. Cambridge University Press, Cambridge. 
(1996b): Survey Evidence on Business Bankruptcychap. 18, pp. 298-328, Corporate Bankruptcy Economic and Legal Perspectives. Cambridge University Press, Cambridge.

\section{Appendix A}

\section{Proof of Proposition 1}

I complete this proof by constructing strategies and beliefs such that the corresponding outcome given by functional equation is an equilibrium outcome.

For any period $t$ and any history with an upper bound on belief of $\theta_{b}$, consider the following profile:

$$
\begin{gathered}
\sigma_{i t}\left(\theta_{b}\right)=\left(p_{1}\left(\theta_{b}\right),\left\{z_{i j} p_{-1}\left(\theta_{b}\right)\right\}_{j \neq i}\right) \\
\text { where } \sum_{j \neq i} z_{i j}=\frac{n-1}{2}, \\
z_{j} \in\{0,1\} \\
\text { and } E\left[z_{i j}|| j \neq i\right]=\frac{1}{2}
\end{gathered}
$$

I claim that the above is an equilibrium. It is easy to show that the above strategies reproduce the continuation values in Program 1. It is also apparent that the beliefs satisfy Bayes' Rule. In this proof I simply check one period deviations to show the strategies are best responses. First consider the proposer. First I show that the proposer chooses the optimal division of resources among the creditors. There are two cases. In the first case the proposer makes an offer that is rejected by all types of the firm, say $P_{t}=\theta_{h}+1$. This earns him the continuation value evaluated at the current upper bound on belief $\theta_{b}$ regardless of the division in his proposed plan among the creditors. Hence any equilibrium profile that includes such an aggregate payment can be a best response whenever making a non-serious offer is a best response. This includes the profile suggested here. 
Suppose it is a best response to make an offer such that some types of the firm accept. I must show that the division described above is optimal. For a particular aggregate payment $P_{t}$, let's derive the highest payoff the proposer can achieve. Note the continuation payoff for all voters are identical at $P_{t}$ given the equilibrium profile (and the restriction on the $z$ 's in (20)). Hence their continuation values are identical. To receive the necessary votes, the plan must satisfy (3) with inequality (or else the proposer can achieve the same welfare by making a trivial offer that satisfies (3)).

$$
\begin{aligned}
p_{j}\left(\frac{F\left(\theta_{b}\right)-F\left(\theta_{a}\right)}{F\left(\theta_{b}\right)}\right)+\delta\left(\frac{1}{n} V\left(\theta_{a}\right)+\frac{n-1}{n} W\left(\theta_{a}\right)\right) & \frac{F\left(\theta_{a}\right)}{F\left(\theta_{b}\right)} \\
& \geq \delta\left(\frac{1}{n} V\left(\theta_{b}\right)+\frac{n-1}{n} W\left(\theta_{b}\right)\right)
\end{aligned}
$$

Hence the only possible deviation is one that satisfies (3) with strict inequality. But such an offer is not a best response to the creditors' strategies, as the proposer could get the requisite votes and a higher share of the revenues by decreasing the offer to the creditor for whom the incentive constraint does not bind.

Next consider the proposer's choice of the aggregate plan $P_{t}^{*}=C\left(\theta_{b}\right)$. Based on the equilibrium strategies for every possible aggregate plan $P_{t}^{*}$, there exists a lowest type $\theta_{a}$ that accepts the plan. This type is given by (2), but with strict equality.

$$
\theta_{a}-p_{i}-\frac{(n-1)}{2} p_{j}=\delta\left(\theta_{a}-C\left(\theta_{a}\right)\right)
$$

It is obvious, in the solution to DP constraint (2) always holds with equality. Hence the proposer always considers the firm's equilibrium strategy when choosing a plan.

The equilibrium strategies give us that the welfare function in (1) corresponds to $V$, Hence the proposer in period $t$ maximizes his choice of an aggregate plan by solving the maximization problem outlined in DP.

For voters and firms, the strategy profile is a best response if they vote ' $\mathrm{Y}$ ' whenever their current payoff is higher than their continuation value. These are precisely the strategies outlined above.

Thus the proposed strategies are an equilibrium.

\section{Proof of Proposition (2)}

Proposition. If $\theta_{l}>0$, the bargaining lasts a finite number of periods.

The proposition can be shown with two lemmas. The first shows that if the upper bound on the belief is sufficiently low the game ends in the current period. The second shows such beliefs are always reached. 
Lemma 1. In any equilibrium there exists a $\theta^{*}>\theta_{l}$, such that if the belief falls below $\theta^{*}$, the game ends in one period, regardless of the proposer. Further, the aggregate payment equals $\theta_{l}$ in such a period.

\section{Proof of Lemma}

First I establish the complete set of strategies for games in their final period. This allows me to explicitly derive the proposer's payoff for settling with all of the remaining types in a period.

If after any relevant history for proposer $i, h_{i}^{t}$, and upper bound on belief, $\theta^{*}$, it is common knowledge the game ends in the current period; then, for the proposer's value, $v_{o}$, and a voter's expected value, $w_{0}$, the proposer solves:

\section{Last Period's Problem}

$v_{0}, w_{0}$ are the fixed point of the following program:

$\left(D P_{0}\right)$

$$
\begin{array}{r}
v_{0}=\max _{p_{i}, p_{j}} p_{i} \\
\text { s.t. } \theta_{l}-p_{i}-\frac{(n-1)}{2} p_{j} \geq 0 \\
p_{j} \geq \delta\left(\frac{1}{n} v_{0}+\frac{n-1}{n} w_{0}\right)
\end{array}
$$

And given $p_{j}$ from $D P_{0}$,

$$
w_{0}=\frac{1}{2} p_{j}
$$

This is the problem studied in Baron and Ferejohn (1989) which they show has a unique solution:

Definition 1. The Baron-Ferejohn payments or $B F$ payments for surplus $s$ are such that:

Let $B F=1-\delta \frac{n-1}{2 n}$.

I. The proposer request $B F$ times $s$ for himself.

II. For half of the remaining creditors he requests $\frac{2(1-B F) s}{n}$ of the surplus

III. For the other half he requests a payment of zero. 
The equilibrium outcome for any game in the final period of bargaining includes dividing $\theta_{l}$ according to the $B F$ payments.

Next I show that there exists a $\theta^{*}$ such that for all beliefs beneath $\theta^{*}$, all plans with $P>\theta_{l}$ are dominated by splitting $\theta_{l}$ according to the $B F$ payments.

The first step in this process is to show that there exists a $\theta^{*}$ such that the expected payoff to the entire set of creditors is maximized by offering $P=\theta_{l}$.

Claim 1. There exists a $\theta^{*}$ such that if $\theta_{b}<\theta^{*}, X\left(\theta_{b}\right)$ is maximized by setting $P=\theta_{l}$.

This is the first part of Lemma 3 in FLT and is not shown here.

Next, I show that for $\theta^{*}$ sufficiently low, the proposer cannot do better in equilibrium by any other strategy than he could do by splitting $\theta_{l}$ according to the Baron Ferejohn payments.

Claim 2. For $\theta_{b}$ sufficiently low, offering $P=\theta_{l}$ to be divided according to the Baron-Ferejohn payments is part of any equilibrium strategy.

To prove this claim I show that whenever $P=\theta_{l}$ maximizes the aggregate payoff $(X)$ to the creditors, I can always find a plan which dominates any plan with aggregate payment $P^{*}>\theta_{l}$.

\section{Proof of Claim}

Suppose not. Consider a candidate equilibrium plan with aggregate payment $P^{*}>\theta_{l}$. This aggregate payment implies a set of payments $\left\{p_{j}^{*}\right\}_{j=1}^{n}$ to the individual creditors and a type $\theta_{1}>\theta_{l}$ that accepts $P^{*}$. Instead of offering the firm $P^{*}$ and the creditors $\left\{p_{j}^{*}\right\}_{j=1}^{n}$, the proposer receives a higher payoff by giving the firm a plan with a lower aggregate payment, $P=\theta_{l}$, and the individual creditors a share of $P$ equal to their expected payoff associated with the original offer and consuming the residual. If the original offer passes the requisite votes, the new offer also passes the requisite vote and approval/ veto decision. Because of the previous claim, the proposer prefers the new plan to the original plan.

Next I complete the original proposition with a lemma that the upper bound on belief $\theta^{*}$ is reached in finite time.

Lemma 2. For any initial belief, $\mu$, there exist a period $T$ such that all types have settled in at most $T$ periods of bargaining. That is within $T-1$ periods the upper bound on beliefs has fallen below $\theta^{*}$.

The above lemma is demonstrated in Lemma 2 in FLT. Hence the proof is omitted.

The lemma completes the proof of Proposition (2).

\section{Proof of Proposition (??)}

For ease of exposition, I assume all relevant functions are differentiable. Consider Program (1). 
Replace the constraint (2) with

$$
p_{i}+\frac{(n-1)}{2} p_{j} \leq P\left(\theta_{a}\right)
$$

where:

$$
P\left(\theta_{a}\right)=(1-\delta) \theta_{a}+\delta C\left(\theta_{a}\right)
$$

For multipliers, $\lambda, \xi, \nu$, the Lagrangian for this problem is:

$$
\begin{aligned}
& p_{i}\left(\frac{F\left(\theta_{b}\right)-F\left(\theta_{a}\right)}{F\left(\theta_{b}\right)}\right)+\delta \frac{1}{n} \frac{X\left(\theta_{a}\right)}{F\left(\theta_{b}\right)}+\lambda\left(p_{i}+\frac{n-1}{2} p_{j}-P\left(\theta_{a}\right)\right) \\
& +\xi\left(p_{j} \frac{\left(F\left(\theta_{b}\right)-F\left(\theta_{a}\right)\right)}{F\left(\theta_{b}\right)}+\delta \frac{1}{n} \frac{X\left(\theta_{a}\right)}{F\left(\theta_{b}\right)}-\frac{1}{n} X\left(\theta_{b}\right)\right)+\nu\left(\theta_{a}-\theta_{l}\right)
\end{aligned}
$$

The F.O.C.'s for an interior optimum for this problem are

$$
\begin{array}{r}
\frac{\left(F\left(\theta_{b}\right)-F\left(\theta_{a}\right)\right)}{F\left(\theta_{b}\right)}=-\lambda \\
-\lambda \frac{n-1}{2}=\xi \frac{\left(F\left(\theta_{b}\right)-F\left(\theta_{a}\right)\right)}{F\left(\theta_{b}\right)} \\
\left(p_{i}+\xi p_{j}\right) \frac{\left(-f\left(\theta_{a}\right)\right)}{F\left(\theta_{b}\right)}+\delta \frac{1}{n} \frac{X_{1}\left(\theta_{a}\right)}{F\left(\theta_{b}\right)}-\lambda P^{\prime}\left(\theta_{a}\right)+\xi \delta \frac{1}{n} \frac{X_{1}\left(\theta_{a}\right)}{F\left(\theta_{b}\right)}=0
\end{array}
$$

Next consider the problem in Program (2).

For the proper choice of $P\left(\theta_{b}\right)$ and $X\left(\theta_{b}\right)$ the proposer's problem is equivalent to:

$$
V\left(\theta_{b}\right)=\left(\max _{\theta_{a}} P\left(\theta_{a}\right)\left(F\left(\theta_{b}\right)-F\left(\theta_{a}\right)\right)+\bar{\delta}(n, \delta) X\left(\theta_{a}\right)\right)
$$

The F.O.C. for an interior optimum for this problem is:

$$
P\left(\theta_{a}\right)\left(-f\left(\theta_{a}\right)\right)+P^{\prime}\left(\theta_{a}\right)\left(F\left(\theta_{b}\right)-F\left(\theta_{a}\right)\right)+\delta\left(\frac{1}{2}+\frac{1}{2 n}\right) X^{\prime}\left(\theta_{a}\right)
$$

Hence any solution to Program 2 must satisfy (30).

Substituting (27) into (28) gives $\xi$

$$
\xi=\frac{n-1}{2}
$$

From here, substituting $\xi$ and $\lambda$ into (29) yields (30) and the F.O.C.'s that determine $g\left(\theta_{b}\right)$ for the two models match.

Thus the belief updating functions $g$ are identical at every period if the $C$ and $X$ functions for the two problems are identical. It is a simple result that identical $g$ functions for different $n$ 's force the $C$ and $X$ functions to be identical. These relationships imply that any $(g, C, X)$ associated with a solution to Program 1 is a solution to Program 2. 


\section{Proof of Theorem 1}

I prove this theorem by deriving the only possible equilibrium recursively from the last period of bargaining. I show that in every period the proposer has a well defined maximization problem with a unique solution. Subscripts refer to additional periods of bargaining not including the current period. I conjecture that the game ends in the current period.

\section{The Zero Iteration}

From previous work, for all $\theta_{b}$, let

$$
\begin{array}{r}
g_{0}\left(\theta_{b}\right)=\theta_{l} \\
C_{0}\left(\theta_{b}\right)=\theta_{l} \\
X_{0}\left(\theta_{b}\right)=\theta_{l} F\left(\theta_{b}\right)
\end{array}
$$

Note this is the unique outcome to the game given the initial conjecture.

From here I conjecture that all bargaining ends in two periods. Note if the game requires two periods to end, then in the final period, the payment in the final period is $C_{0}\left(\theta_{b}\right)$. The expected revenues to the creditor in the final period are $X_{0}\left(\theta_{b}\right)$.

The First Iteration

Given $C_{0}$, and $X_{0}$; for all $\theta_{b}$, let

$$
\begin{array}{r}
g_{1}\left(\theta_{b}\right)=\arg \max _{\theta_{a}}\left((1-\delta) \theta_{a}+\delta C_{0}\left(\theta_{a}\right)\right)\left(F\left(\theta_{b}\right)-F\left(\theta_{a}\right)\right)+\bar{\delta} X_{0}\left(\theta_{a}\right) \\
C_{1}\left(\theta_{b}\right)=(1-\delta) g_{1}\left(\theta_{b}\right)+\delta C_{0}\left(g_{1}\left(\theta_{b}\right)\right) \\
X_{1}\left(\theta_{b}\right)=C_{1}\left(\theta_{b}\right)\left(F\left(\theta_{b}\right)-F\left(g_{1}\left(\theta_{b}\right)\right)\right)+\delta X_{0}\left(g_{1}\left(\theta_{b}\right)\right)
\end{array}
$$

The maximum theorem gives that $g_{1}$ is a UHC correspondence. An argument in Ausubel and Deneckere (1989) (Proposition 4.3) gives that $g_{1}$ is single valued, except possibly in the initial period over a countable set. Hence $C_{1}$ and $X_{1}$ are continuous functions and are uniquely defined. I note that having completed the first iteration, I can place a restriction on the highest upper bound such that bargaining lasts one additional period.

$$
\theta_{1}=\sup _{\theta_{b}}\left\{\theta_{b}: g_{1}\left(\theta_{b}\right)=\theta_{l}\right\}
$$

Lemma 1 requires $\theta_{1}>0$ and the equilibrium outcome has been uniquely determined for all $\theta_{b}<\theta_{1}$. 
Given that $t$ iterations have been completed and the equilibrium outcome has been uniquely determined for all $\theta_{b}<\theta_{t}$, I can perform the $t+1$ iteration:

\section{The $t+1$ Iteration}

Given $C_{t}$, and $X_{t}$; for all $\theta_{b}$, let

$$
\begin{array}{r}
g_{t+1}\left(\theta_{b}\right)=\arg \max _{\theta_{a}}\left((1-\delta) \theta_{a}+\delta C_{t}\left(\theta_{a}\right)\right)\left(F\left(\theta_{b}\right)-F\left(\theta_{a}\right)\right)+\bar{\delta} X_{t}\left(\theta_{a}\right) \\
C_{t+1}\left(\theta_{b}\right)=(1-\delta) g_{t+1}\left(\theta_{b}\right)+\delta C_{t}\left(g_{t+1}\left(\theta_{b}\right)\right) \\
X_{t+1}\left(\theta_{b}\right)=C_{t+1}\left(\theta_{b}\right)\left(F\left(\theta_{b}\right)-F\left(g_{t+1}\left(\theta_{b}\right)\right)\right)+\delta X_{t}\left(g_{t+1}\left(\theta_{b}\right)\right)
\end{array}
$$

Again unless $\theta_{b}=\theta_{h}$, the solution to the above problem is unique. Once this iteration is complete, I have uniquely described equilibrium behavior for all upper bounds on beliefs $\theta_{b} \leq \theta_{t+1}$ where given $\theta_{t}, \theta_{t+1}$ is defined as:

$$
\theta_{t+1}=\sup _{\theta_{b}}\left\{\theta_{b}: g_{t+1}\left(\theta_{b}\right) \leq \theta_{t}\right\}
$$

Since the bargaining lasts a finite number of periods, after at most $T$ iterations, $\left(g_{T}, C_{T}, X_{T},\right)$ is the solution to the simpler functional equation for a given value of $\theta_{h}$. Since the argument in Ausubel and Deneckere (1989) does not apply in the initial period, $g_{T}$ may not be single valued. But the monotonicity of the problem guarantees that $g_{T}$ is single valued except at most a countable set, which completes the existence and uniqueness results.

\section{Proof of Lemma ??}

Consider an upper bound on beliefs $\theta_{h}$, that is small enough such that for either $n$ the game ends in no more than two periods of bargaining. Hence the proposer with such a belief solves:

$$
g_{1}\left(\theta_{b}\right)=\arg \max _{\theta_{a}}\left((1-\delta) \theta_{a}+\delta \theta_{l}\right)\left(F\left(\theta_{h}\right)-F\left(\theta_{a}\right)\right)+\bar{\delta} \theta_{l} F\left(\theta_{a}\right)
$$

Consider an upper bound on beliefs, $\theta_{N}$, such that $\theta_{N}$ equals the supremum of all upper bounds on beliefs for which $g_{N}\left(\theta_{N}\right)=\theta_{l}$ when $n=N$. It follows that:

$$
(1-\delta)\left(F\left(\theta_{N}\right)-F\left(\theta_{l}\right)\right)-\theta_{l} f\left(\theta_{l}\right)=-\bar{\delta}_{N} \theta_{l} f\left(\theta_{l}\right)
$$

where $N$ is an argument in $\bar{\delta}_{N}$ When the F.O.C. is evaluated for $n=1$ it becomes,

$$
(1-\delta)\left(F\left(\theta_{N}\right)-F\left(\theta_{l}\right)\right)-\theta_{l} f\left(\theta_{l}\right)>-\bar{\delta}_{1} \theta_{l} f\left(\theta_{l}\right)
$$


Hence, for $n=1$ the solution to the two period problem is strictly greater than $\theta_{l}$. (Though not shown, this can be seen by examining the F.O.C evaluated at $\theta_{N}$ instead of $\theta_{l}$ for $n=1$ where the inequality is flipped.)

And, for all $\theta_{h}$ in a neighborhood of $\theta_{1}$, the lemma holds.

\section{Proof of Proposition 3}

To update notation, let $X$ be a function of $\theta_{h}, n$ and also $\delta$. First I begin with a well known property of these models which is the basis of the proof.

\section{Property 1. Revenues satisfy Coase Conjecture}

Let $\delta \rightarrow 1$. Then, for any $\theta_{h}$, and any bankruptcy system:

$$
X\left(\theta_{h}, 1, \delta\right) \downarrow 0
$$

The proof of the above property is in GSW and is not shown here due to its length.

It is convenient to rewrite the problem to find a more manageable measure of welfare. I prefer to minimize the deadweight or social losses. Hence I define a new term, $S L\left(\theta_{h}, n, \delta\right)$, which is the lost surplus due to delay for a bankruptcy system with an upper bound of $\theta_{h}$ and a linear belief updating function $g$ with slope $\theta_{a}(n, \delta)$.

$$
S L\left(\theta_{h}, n, \delta\right)=\sum_{t}(1-\delta) \delta^{t} \int_{0}^{\theta_{a t}\left(\theta_{h}(n, \delta)\right)} \theta f(\theta) d \theta
$$

Since $f$ is uniform this equals:

$$
\begin{array}{r}
=\sum_{t=1}^{\infty}(1-\delta) \delta^{t} \frac{\left(\theta_{a t}\left(\theta_{h}(n, \delta)\right)\right)^{2}}{2} \\
=\frac{1}{2} \sum_{t=1}^{\infty}(1-\delta) \delta^{t}\left(\theta_{a}(n, \delta)\right)^{2 t} \theta_{h}^{2} \\
S L\left(\theta_{h}, n, \delta\right)=\frac{(1-\delta) \theta_{a}(n, \delta)^{2} \theta_{h}^{2}}{2\left(1-\delta \theta_{a}(n, \delta)^{2}\right)}
\end{array}
$$

I require one more item of notation before I can state the original problem in a form I prefer. The revenues creditors achieve both inside and outside bankruptcy are $R\left(\theta_{h}, n, \delta\right)$ where $\theta_{h}$ is the highest type in bankruptcy, $n$ the number of creditors who bargain with the firm and $\delta$ the discount factor.

$$
R\left(\theta_{h}, n, \delta\right)=X\left(\theta_{h}, n, \delta\right)+\theta_{h}\left(1-F\left(\theta_{h}\right)\right)
$$

The choice of system that maximizes ex-ante welfare can be found by solving a related problem. In the UK, for any $n$ the revenues in bankruptcy are identical. Hence what is indeterminant is whether $I-X\left(\theta_{h}, 1\right)$ is supplied by creditor one or by the other $n-1$ creditors. 
Hence without loss of generality, I can assume this finance is supplied by the receiver. Thus the problem which defines ex-ante welfare is identical in the UK system to the US system with one creditor. Thus fix $n$ as either 1 or $N>1$. Consider the following problem with the US law.

$$
\begin{array}{r}
\theta_{h}, n \in\{1, N\}=\arg \min S L\left(\theta_{h}, n, \delta\right) \\
\text { such that } R\left(\theta_{h}, n, \delta\right)=I
\end{array}
$$

If $N$ solves the above problem, the US system maximizes welfare. If not welfare is equivalent in the two systems.

Now given this alternative form of the problem, I show that any $N>1$ such that the above problem is well defined solves the problem for $\delta$ sufficiently high.

To prove the proposition, fix $N>1$ and $I$ and pick $\epsilon$ arbitrarily small.

Let $\theta_{h}(N, \delta)$ and $\theta_{h}(1, \delta)$ be the values of $\theta_{h}$ associated with the $N$ and one creditor systems at $I$. Note both terms increase in $\delta$. Also choose $\delta$ such

$$
\theta_{h}(N, \delta)-\theta_{h}(1, \delta)<\epsilon
$$

Such a choice is possible since for high discount factors, the one creditor system produces arbitrarily small revenues in bankruptcy. Also note that for $\delta$ sufficiently high, $\theta_{h}(1, \delta)$ is bounded away from zero. Next I transform the SL function so that it does not converge to zero as $\delta$ converges to one. Let $S L B\left(\theta_{h}, n, \delta\right)=\sqrt{\frac{S L\left(\theta_{h}, n, \delta\right)}{1-\delta}}$

Note immediately that $S L B$ is continuous over the relevant range of every variable.

Next I use identity (21) to bound $S L B\left(\theta_{h}, 1, \delta\right)-S L B\left(\theta_{h}, N, \delta\right)$ from below by using the implied differences in the belief updating function. Note the $\beta$ which solves equation (21) is continuous in $\delta$. Let $\theta_{a}=\beta$ and write it as a function of $N$ and $\delta$. Take the limit of $\theta_{a}(n, \delta)$ as $\delta$ goes to one. For $n=1$ this limit is one. For $n=N$, this limit is strictly bounded away from 1. Consider:

$$
M\left(\delta^{*}\right)=\inf _{\delta \geq \delta^{*}} \frac{\theta_{a}(1, \delta)}{\sqrt{1-\delta \theta_{a}(1, \delta)^{2}}}-\frac{\theta_{a}(N, \delta)}{\sqrt{1-\delta \theta_{a}(N, \delta)^{2}}} .
$$

$M$ is continuous and converges to $\infty$. For $\delta^{*}$ sufficiently high this number must be bounded away from zero.

Also let $c \geq \sup \frac{\theta_{a}(N, \delta)}{\sqrt{1-\delta \theta_{a}(N, \delta)^{2}}}$ which is bounded from above. Also choose $c$ to be finite. Consider

$$
S L B\left(\theta_{h}(1, \delta), 1, \delta\right)-S L B\left(\theta_{h}(1, \delta), N, \delta\right)
$$

which is

$$
\geq M(\delta)\left(\theta_{h}(1, \delta)\right)-c *\left(\theta_{h}(N, \delta)-\theta_{h}(1, \delta)\right)
$$

For $\epsilon$ sufficiently small ( $\delta$ sufficiently close to one), the first term is bounded away from zero, whereas the second term converges to zero. Hence, 


$$
S L B\left(\theta_{h}, 1, \delta\right)-S L B\left(\theta_{h}, N, \delta\right)>0
$$

which proves the proposition.

\section{Appendix C: Brief Detail on Data}

The only numbers that are original to my research are the numbers on delays in bankruptcy. The numbers for US delays are from Bankruptcy DataSource which covers firms of assets of more than 50 million dollars. The data comes from a sample of approximately 200 firms. Firms that were not successfully reorganized were removed from the sample. The two events from the which the duration is taken are the firm's entrance in to Chapter 11 and the confirmation of the plan. The later date is very close to the formal conclusion of bankruptcy, but is available more frequently. All firms in the sample exited bankruptcy between January 1995 December 2001. The firms in the sample are attached as Table 1. This number closely tracks what other authors have found. See in particular, White (1996b) and Altman and Eberhart (1999).

The British data is taken from the ICC Directory of UK Companies. This source consists of firms that exited Receivership between August 1997 and November 2003. The relevant events for the duration number are the "Appointment of the Receivership" and the "Notice of Ceasing to Act as A Receiver or a Manager." I took a subsample ${ }^{16}$ of approximately 400 firms from the data. Firms that failed to successfully reorganize ${ }^{17}$ were removed from the sample and the time between the two events for the remaining firms is attached as Table 2. A question may be asked how robust this observation is to other definitions of delays from the data. Particularly, under UK law, receivers are required to submit a plan of reorganization to the creditors close to the initiating of receivership. There is no vote on the plan. Using the submission of a plan to date the end of uncertainty under receivership would greatly shorten the delays for the UK, but would also not capture the tenuous nature of such plans, which seldom end a firm's receivership or guarantee the firm will avoid liquidations. The theory does not predict that reorganizations which eventually lead to liquidation are faster under the US system. The current management's consent to return as a manager is an important element of the theory.

\footnotetext{
${ }^{16}$ The randomization device chosen was to select firms that used the abbreviation Ltd. in their title instead of the full word Limited.

${ }^{17}$ I do not consider firms sold as a going concern to be successfully reorganized. I adopt this convention to be consistent with the theory in this paper.
} 
Figure 1: Timelines
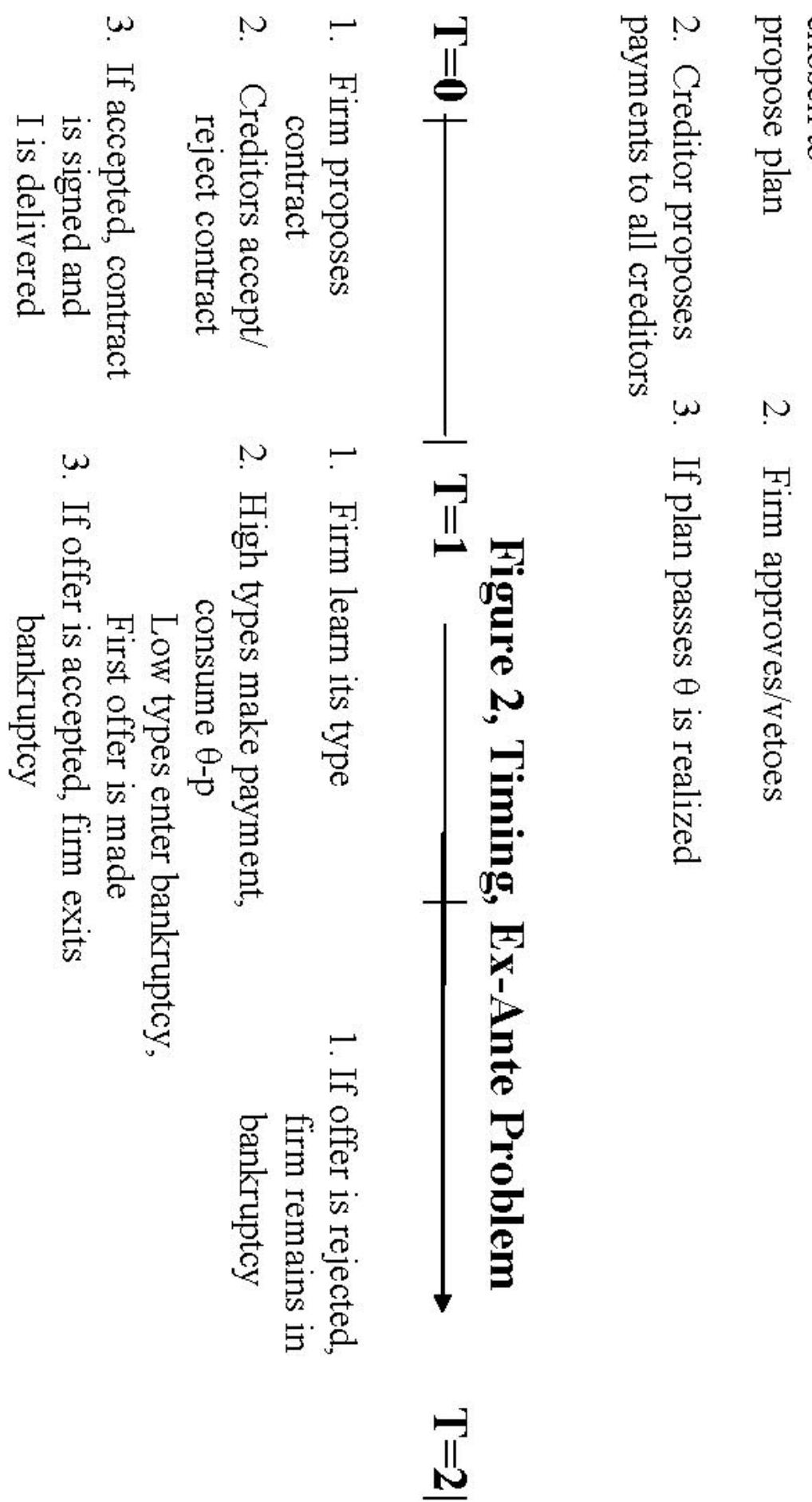
Figure 2: Example 1: No Gap Case

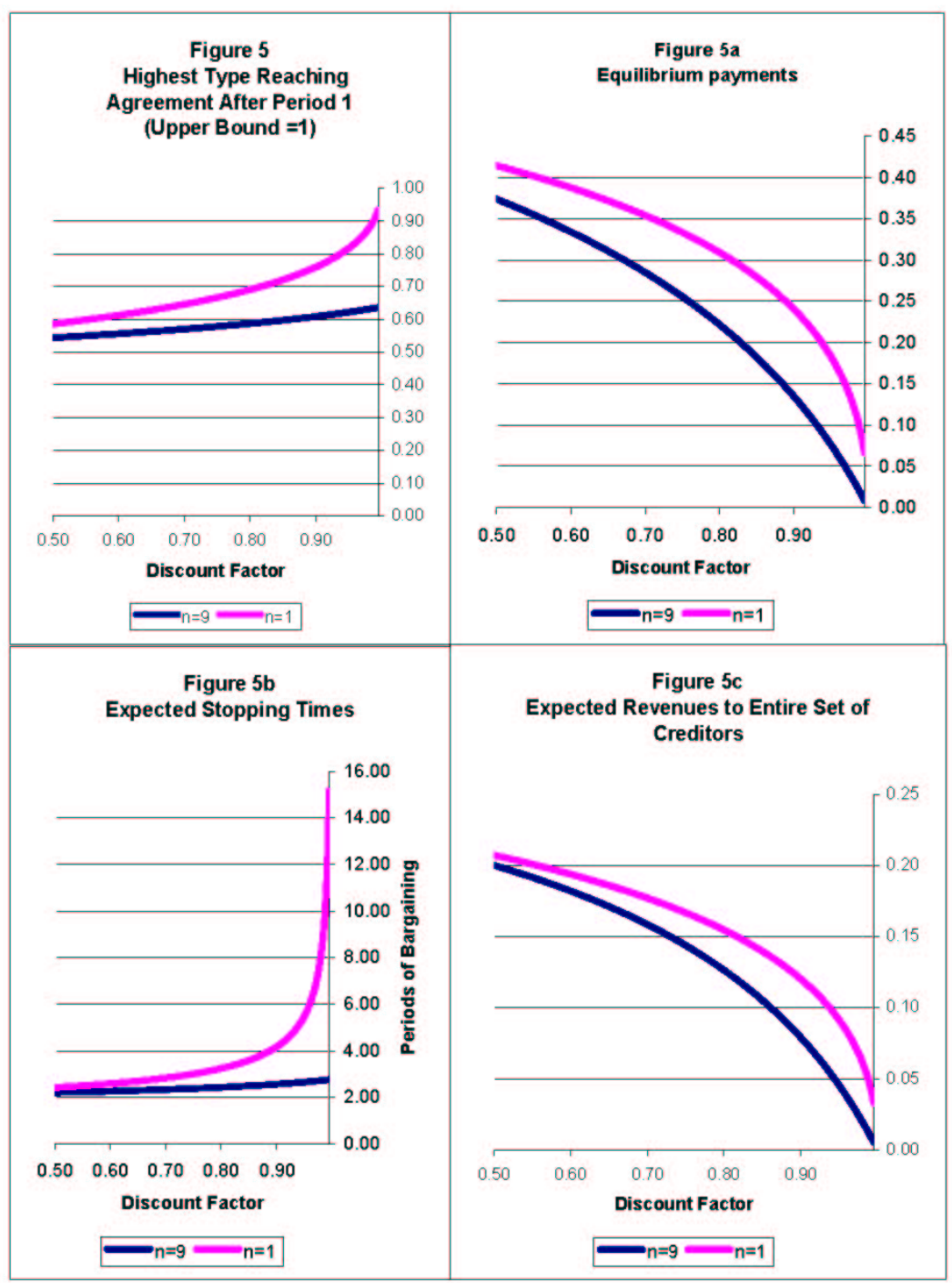


Figure 3: Example 2: Gap Case

\section{Expected Stopping Time, Uniform Distribution, Gap Case}

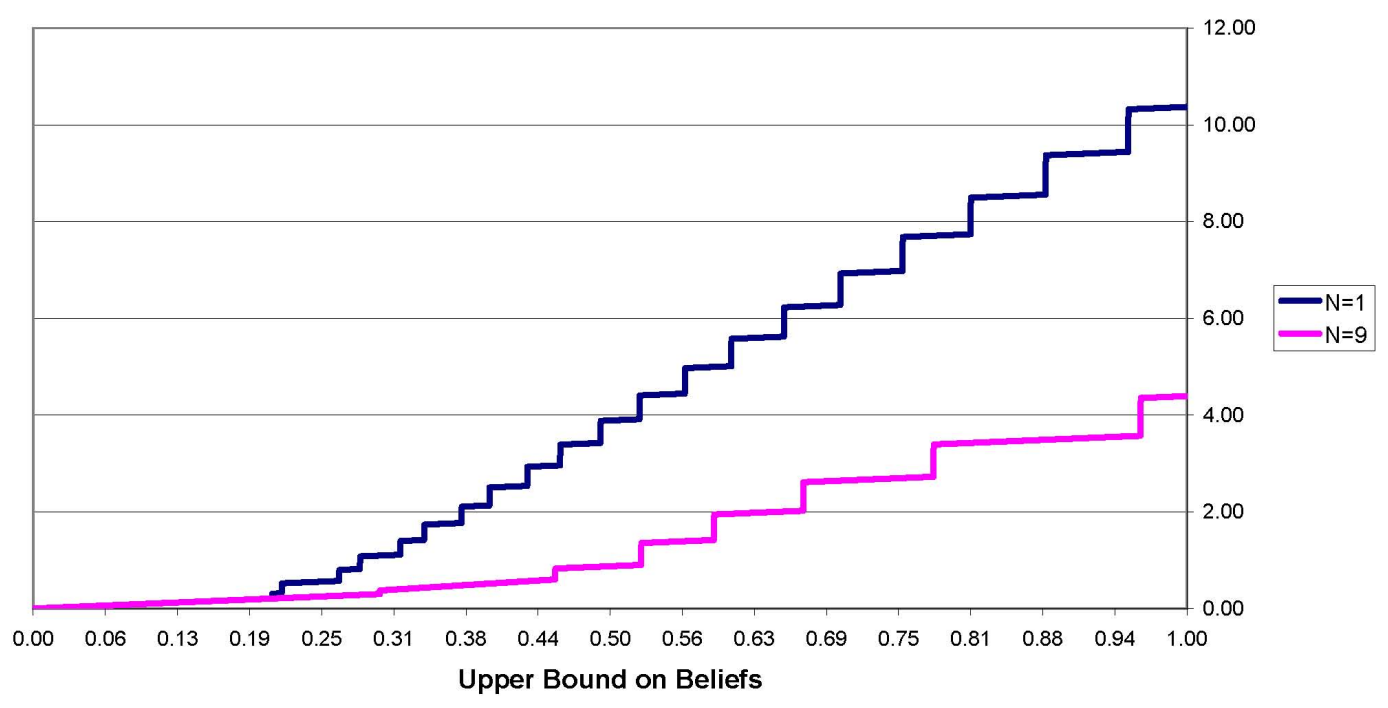


Figure 4: US Data on Durations

\section{Table 1}

\section{Length of US Procedures}

$\begin{array}{llll}\text { US Firms } & \text { Months In Negotiation } & \\ \text { Adience } & 4 & \text { Marvel Entertainment } & 18 \\ \text { Anchor Glass } & 4 & \text { Grossman Inc } & 20 \\ \text { Penn Traffic } & 4 & \text { Leaseway } & 20 \\ \text { Republic Health } & 4 & \text { Sun Healthcare } & 23 \\ \text { First Wave Marine } & 5 & \text { Amalgamated } & 24 \\ \text { LA Gear } & 5 & \text { Americaold } & 26 \\ \text { Marcade Group } & 6 & \text { Farley } & 26 \\ \text { US Leather } & 6 & \text { Victory Markets } & 26 \\ \text { Americtruck } & 7 & \text { First Executive } & 28 \\ \text { Creditrust } & 7 & \text { Hechinger } & 28 \\ \text { First Merchant } & 7 & \text { Lermont \& Hauspice } & 28 \\ \text { Crowey, Maher \& Company } & 8 & \text { Standard Brad Painting } & 28 \\ \text { Kitty Hawk } & 8 & \text { Circle K } & 33 \\ \text { Leasing Solutions } & 8 & \text { America West } & 36 \\ \text { Wireless One } & 9 & \text { Olympia \& Yort } & 39 \\ \text { Global Ocean } & 10 & \text { City Bank of Texas } & 47 \\ \text { 50\% off Store } & 12 & \text { F.C. I. } & 56 \\ \text { Brothers Gourment Coffee } & 14 & \text { Edison Brothers } & 65 \\ \text { Grand Union Co } & 15 & \text { Best Products } & 78 \\ \text { Lomas } & 15 & \text { First Republic Bank } \\ \text { Stage Stores } & 15 & \text { Mean } & 90 \\ \text { Alexanders } & 16 & \text { St. Deviation } & 21.5 \\ \text { Harvard } & 16 & & 19 \\ \text { American Carriers } & 17 & & \\ \text { Big V } & 17 & & \\ \text { Brendles } & 17 & & \\ \text { Northwestem Steel \& Wire } & 17 & & \\ \text { Marvel Entertainment } & 18 & & \end{array}$

${ }^{*}$ Non Random Sample from Bankruptcy Datasource Marks the difference between filing and confirmation date for firms that exited bankruptcy no sooner than 1990 
Figure 5: UK Data on Durations

\section{Table 2}

\begin{tabular}{|c|c|c|c|c|}
\hline \\
\hline \multicolumn{5}{|c|}{ UK Firm Months Spent in Negotiations } \\
\hline MVT & 3 Blackspar & $31 \mathrm{ML}$ Group & 47 FIL Group & 8 \\
\hline Hargraves & 4 Landis & 31 Chipwood & 48 Chequers & 86 \\
\hline Pebberville & 4 NECA Holding & 31 Campbell \& A. & 50 Connaught Com. & 8 \\
\hline Franco & 6 Palmgrade & 31 Hey \& Croft & 50 Newspace Grp & \\
\hline TT & 6 Stewart Mech & 31 Int. Food & 51 BIMEC Ind. & 9 \\
\hline Daffryn & 11 Image & 32 Essex & 53 Land and Urban & 9 \\
\hline WTC & 12 Finecare & 33 Energy & 54 Broadwell Land & 10 \\
\hline DSB & 14 MEI Ind & 33 Abbycraft & 55 Result & 10 \\
\hline Floorspec & 15 Harlequin & 34 Toriamai & 56 Navigations & 108 \\
\hline Heller & 15 London\& Co & 35 Rothwell & 57 McLaughlin \& Harvey & 11 \\
\hline IWEC & 19 Whitton & 35 Upperfield & 58 Advanced Business & 11 \\
\hline Beaumont & 21 Britt Timber & 36 Lornging Forn & 59 Coloroll Group & 1 \\
\hline AO Real & 22 Beaconpoint & 37 London Wall & 60 Orlinworth & 11 \\
\hline DDG & 22 Cardiff & 37 Colorvision & 63 Hughes Food Group & 12 \\
\hline Leading & 23 Metraking & 37 LI Realisation & 65 Pennant Properties & 14 \\
\hline Lledo & 23 Car Group & 38 Eurocrush & 66 Rockwood Holdings & 14 \\
\hline Tyron & 25 Prince & 39 Sale Tilney & 71 Mean & 5 \\
\hline Beach Home & 26 Total Office $\mathrm{Gpp}$ & 40 Kendell & 71 Standard Deviation & \\
\hline Chadwick Web & 26 Tring & $40 \mathrm{HAL}$ & 71 & \\
\hline NFF & 26 Wildwood G C & 40 Binary $R$. & 71 & \\
\hline Four Seasons & 27 Priorywood & $45 \mathrm{BCl}$ Europe & 71 & \\
\hline Reading $\mathrm{L}$. & 28 Blackwall & 46 Tysons & 75 & \\
\hline Worthfine Fr. & 28 Pavilion Leisure & 46 DTP Real. & 75 & \\
\hline Gogas & 29 Miskin Group & 46 Donelon Tyson & 75 & \\
\hline Archway & 30 Rider Fenn \& Co & 46 Equity General & 79 & \\
\hline Versailes & 30 Abelmart & 47 Omega Group & 83 & \\
\hline
\end{tabular}

Source ICC Directory of UK Companies 